\title{
LOS DIBUJOS SEVILLANOS DE RICHARD FORD REVISITADOS: MODOS DE MIRAR EL PAISAJE URBANO
}

\author{
THE SEVILLIAN DRAWINGS BY RICHARD FORD \\ REVISITED: WAYS OF SEEING THE URBAN LANDSCAPE
}

\author{
F. JaVier Rodríguez Barberán, Marta Cruz García \\ Universidad de Sevilla, España \\ barberan@us.es - marta.cg91@gmail.com
}

Los dibujos que Richard Ford, el famoso viajero inglés autor del Manual para viajeros por España, realizó en Sevilla entre 1830 y 1833 son una de las fuentes claves para la iconografía de la ciudad. Este conjunto, estudiado en el contexto de su corpus de obras españoles, admite con su complejidad nuevas interpretaciones. El artículo se propone analizar el proceso de realización de ese trabajo y sus propias características - cronología; modos de ver- para entender de qué modo se produjo la traslación al papel del paisaje urbano, ese paisaje tan rico precisamente por el contraste entre la continuidad y las transformaciones.

Palabras clave: Richard Ford, Viajeros siglo XIX, Iconografía de Sevilla, Dibujo y fotografía siglo XIX

The drawings that Richard Ford, the famous English traveller author of the Hand-Book for Travellers in Spain, made in Sevilla from 1830 to 1833 are a key source to the iconography of the city. These works can incorporate new interpretations when considered the context of Ford's whole corpus of Spanish drawings. The intention of this text is the analysis of the making process of this work and its own characteristics - chronology; ways of seeing-in order to understand how the urban landscape was reflected. We talk about a rich urban landscape because of the contrast between continuity and transformations.

Keywords: Richard Ford, $19^{\text {th }}$ century travellers, Iconography of Seville, $19^{\text {th }}$ century drawings and photography.

Pertrechado con sus útiles de dibujo, Richard Ford, que apenas cumplía su segunda semana de estancia en Sevilla, se dirigió a las afueras de la misma. Desde un punto cercano a la Puerta de la Carne realizó el que probablemente sea el primer dibujo de los muchos que llevó a cabo de la ciudad; no eligió ningún monumento singular, o una zona especialmente pintoresca. Ante él se desplegaba un 
terreno baldío, al fondo del cual aparecía una puerta en la muralla; más allá, la estructura de un antiguo acueducto y, tras ella, los volúmenes de un edificio religioso. Anotó: "Puerta de Carmona / Sn. Agostino (sic) / Caños de C ...". No se olvidó de consignar, en inglés, la fecha: era el 3 de diciembre de $1830{ }^{1}$.

Desde que en 1963 Sir Brinsley Ford y D. Diego Angulo dieran a conocer una selección de los dibujos sevillanos del viajero inglés ${ }^{2}$, éstos se han convertido en una de las más importantes referencias para la iconografía histórica de la ciudad. Bien incluidos dentro de un panorama más extenso ${ }^{3}$, o analizados de modo singular ${ }^{4}$, el centenar largo de dibujos y acuarelas de Ford retratan la ciudad a la que lentamente llegan las decisivas transformaciones que el siglo XIX incorporará a su fisonomía urbana. ¿Qué le otorga a la obra de Ford su singularidad? Y, sobre todo, ¿qué la hace susceptible de nuevas aproximaciones? A ello pretende responder este artículo.

Es necesario advertir antes que nada que la lectura de los dibujos no está marcada por un contexto único, lo cual nos permite adoptar también puntos de vista diferentes que, sin embargo, parecen obligados a complementarse. Así, es necesario que las obras sevillanas no sean aisladas del conjunto de las que Ford fue creando durante sus casi tres años de estancia en España, y que han sido objeto de una revisión actualizada en fechas muy recientes ${ }^{5}$. Los dibujos y apuntes de Ford pueden ser estudiados de modo diacrónico - prestando atención a sus itinerarios por nuestro país o a las estancias prolongadas en Granada y, por supuesto, Sevilla ${ }^{6}$ o o analizados con una perspectiva transversal, en la que el reconocimiento de los motivos sea un medio para aproximarse al universo mental de Ford, esto es, al contexto cultural y de mentalidades en el cual fueron creados ${ }^{7}$. La primera lectura tiene que ver con el establecimiento de unas pautas que permitan comprender las condiciones en que la obra se ejecuta y el encaje que la misma tiene en el viaje, entendido éste como se venía haciendo sobre todo desde

${ }^{1}$ Reproducido en RODRÍGUEZ BARBERÁN, F. Javier (ed.): La Sevilla de Richard Ford (1830-1833). Sevilla, 2007, p. 54 (cat. no 95).

${ }^{2}$ FORD, Brinsley. Richard Ford en Sevilla. Madrid, 1963 (con notas a las láminas de Diego Angulo).

${ }^{3}$ CALVO SERRALLER, F. et al.: Iconografía de Sevilla: 1790-1868. Madrid, 1991

${ }^{4}$ RODRÍGUEZ BARBERÁN, F. Javier (ed.): op. cit.

${ }^{5}$ RODRÍGUEZ BARBERÁN, F. Javier (ed.): Richard Ford. Viajes por España (18301833). Madrid, 2014.

${ }^{6}$ Ibídem. Véanse de modo específico los textos de GÁMIZ GORDO, Antonio: "Paisajes dibujados. Las rutas de Ford”, pp. 113-273 passim.

${ }^{7}$ Ibíd. Para esta mirada específica véase RODRÍGUEZ BARBERÁN, F. Javier: "Una colección invisible. Los dibujos españoles de Richard Ford”, en Idem (ed.): Richard Ford ..., op. cit., pp. 29-71 
el siglo XVIII, es decir, como un auténtico proyecto de formación intelectual ${ }^{8}$. La segunda apunta justo a la visión que, ya sea de un país, ya de una ciudad, Ford construye con sus dibujos. Para ello es esencial asumir la condición de éste, tantas veces comentada, como artista amateur, sin que ello implique carga peyorativa alguna $^{9}$ : este hecho se ha subrayado siempre para marcar las distancias, por ejemplo, con dos contemporáneos y amigos suyos, John F. Lewis y David Roberts, para quienes el viaje por España supuso un hito en sus carreras. Pero es precisamente esta diferencia la que, lejos de ser un lastre, le aporta a la obra de Ford una perspectiva relativamente inusual: sus dibujos no son ejecutados como parte de un proyecto legítimamente ambicioso de promoción personal, ni responden a encargo alguno. Son su modo de aproximarse analíticamente al mundo que le rodea y con ellos quiere conservar un registro personal de lo visto. A esta idea primera se le van a añadir otros elementos: su educación en Inglaterra y el balance de sus primeros viajes por Europa; las diferencias que probablemente advirtió entre la imagen de España que tenía desde su país y la que se desplegó ante él ${ }^{10}$; y sobre todo, la propia evolución del mundo intelectual del Viejo Continente, donde las ideas de la Ilustración, enfrentadas con las transformaciones económicas, políticas y sociales, dejaban ya paso a la nueva realidad del Romanticismo.

Siendo estas cuestiones decisivas, existe otro elemento que, si cabe, resulta aun más enriquecedor. La figura de Richard Ford, antes de que sus dibujos fueran revelados ${ }^{11}$, era conocida a través de un texto fundamental en la literatura de viajes del XIX, A Hand-Book for Travellers in Spain ${ }^{12}$, publicado en Londres en

${ }^{8}$ Sobre este tema, vid. LUZÓN NOGUÉ, José María (ed.): El "West Morland". Recuerdos del Grand Tour. Madrid, 2002. En la extensa bibliografía sobre los dibujos de viajes, y aunque está más centrado en los realizados por arquitectos, una importante contribución reciente es MELIÁN GARCÍA, Ángel (ed.): El dibujo de viaje de los arquitectos. Actas del XV Congreso Internacional de Expresión Gráfica Arquitectónica. Las Palmas de Gran Canaria, 2014.

${ }^{9}$ La primera aproximación a su obra ya lo puso de manifiesto. Vid. FORD, Brinsley: "J. F. Lewis and Richard Ford in Seville, 1832-1833". The Burlington Magazine for Connoisseurs, vol. 80, $\mathrm{n}^{\circ}$ 470, 1942, pp. 124-129. Un mayor desarrollo de estas ideas por el mismo autor puede verse en "Richard Ford as a Draughtsman", en IDEM: Richard Ford in Spain. London, 1974, pp. 31-35.

${ }^{10}$ La biografía canónica de Ford es la de ROBERTSON, Ian: Richard Ford 1796-1858. Hispanophile, Connoisseur and Critic. Wilby (UK), 2004. Para una actualización de contenidos, sobre todo en lo referente al viaje por España, vid. IDEM: "Viajes de Ford por España”, en RODRÍGUEZ BARBERÁN, F. Javier (ed.): Richard Ford ..., op. cit., pp. 73-111

${ }^{11}$ El proceso de difusión de los dibujos de Ford ha sido estudiado sistemáticamente en RODRÍGUEZ BARBERÁN, F. Javier: “Una colección invisible ...”, op. cit., pp. 29-41

${ }^{12}$ FORD, Richard: Manual para viajeros ... y lectores en casa ... (Madrid, $1980 \ldots-10$ vols.-; ed. no completa, con traducción de Jesús Pardo de Santayana). Existe un edición reciente (Madrid, 2008 -7 vols.-), que traduce ya la obra en su integridad. 
1845. El libro, que unía a su carácter de guía el de una obra con voluntad enciclopédica sobre nuestro país, fue pieza clave para el conocimiento del mismo por parte del público cultivado anglosajón hasta principios del siglo XX. La tantas veces comentada imagen de España tiene en el Manual una de sus principales fuentes, y por ello es precisamente importante saber cómo Ford, pasada ya más de una década desde estancia en la Península, pudo reconstruir de modo tan prolijo -hablamos de una obra editada en dos volúmenes y que superaba las mil páginas- el mundo que se había desplegado ante él. Evidentemente contó con la abundante biblioteca que había adquirido en España e incluso luego incrementado en Inglaterra; tuvo a sus corresponsales en nuestro país, especialmente al erudito Pascual de Gayangos, como soporte inestimable ${ }^{13}$; pero sobre todo debió recurrir una y otra vez al registro de sus días, y aquí es donde, entiendo, debieron reaparecer los dibujos. Aunque Ford llevó consigo siempre lo que denominaríamos cuadernos de viaje ${ }^{14}$, éstos contenían sobre todo notas de índole práctica, y apenas algún boceto, sobre todo de personajes que le llamaron en su momento la atención; lo realmente decisivo como memoria visual eran sus más de quinientos dibujos y apuntes, repletos de paisajes y ciudades de España, de lugares pintorescos, de ruinas, monumentos y caminos. Más allá de los debates en torno a la objetividad de la mirada de Ford, la relación que es posible establecer entre su obra y la irrupción, poco tiempo después, de la fotografía, o la forma en que la realidad es observada a través de las notas culturales que marcan su época ${ }^{15}$, lo único incontestable es la enorme extensión y variedad del corpus gráfico fordiano. Ello se hace patente, desde luego, en todas sus rutas por España, pero donde adquiere una dimensión plena es en las dos ciudades que eligió como residencia para él y su familia, y punto de partida para esas rutas: Granada y Sevilla. No obstante, y aun cuando el número de dibujos realizados en ambas es bastante semejante, hay una diferencia notable: el protagonismo que en el primero de los casos tiene un conjunto, la Alhambra. El monumento islámico en sí, con sus espacios singulares y detalles arquitectónicos, las vistas de éste desde la distancia o las perspectivas de la ciudad desde la colina que el mismo ocupa, representan un porcentaje enorme del total de las obras granadinas ${ }^{16}$. En Sevilla, la diversidad es mayor, y el retrato de la misma se hace más complejo. Precisamente por

${ }^{13}$ HITCHCOCK, Richard (ed.): Richard Ford's Letters to Gayangos. Exeter, 1974

${ }^{14}$ Lamentablemente, y por una decisión singular de Richard Ford, casi todos fueron destruidos antes de su muerte. Solo se conservan dos en poder de los descendientes. Vid. FORD, Brinsley: Richard Ford..., op. cit., p. 81.

${ }^{15}$ Una visión actualizada de esto puede verse en RODRÍGUEZ BARBERÁN, F. Javier: "Una colección invisible...", op. cit., pp. 41-71.

${ }^{16}$ GÁMIZ, Antonio: "Dibujos de Richard Ford en Granada. Nuevos puntos de vista sobre su paisaje urbano (1831-1833)", en RODRÍGUEZ BARBERÁN, F. Javier (ed.): La Sevilla..., op. cit., pp. 86-109. Una visión actualizada puede verse también en GÁMIZ, 
esto, entiendo, cabe siempre realizar nuevas aproximaciones, lecturas que, alimentándose de las ya hechas, muestren aspectos que habían quedado oscurecidos por los más evidentes; o que sirvan, sobre todo, para observar el presente con la pluralidad que su propia naturaleza demanda.

Los análisis llevados a cabo en torno a la obra sevillana de Richard Ford no han abordado hasta ahora un elemento que, a la vista de lo que sabemos sobre todo el conjunto español, abre un camino que merece ser explorado: me refiero a la cronología de sus dibujos ${ }^{17}$. Como ya hemos señalado al principio del texto, el 3 de diciembre de 1830, tras haber llegado a la ciudad entre el 19 y el 20 de noviembre, Ford firma su primera obra en la ciudad. Entre esa vista de la Puerta de Carmona y su entorno y una pequeña aguada, fechada en marzo de 1833 -la familia Ford abandonó la ciudad definitivamente a finales del mes siguiente-, y que muestra a su hijo Francis Clare "Brubby" vestido de majo ${ }^{18}$, el viajero inglés va a llevar a cabo uno de los más amplios repertorios iconográficos de la ciudad. Del centenar de obras conservadas, más de una treintena cuentan con una datación exacta: ello no es insólito si se hace la comparación con los apuntes que realiza en paralelo a sus rutas españolas, y parece formar parte del afán de Ford por darle a los dibujos un perfil claramente documental. La diferencia principal estriba en que, mientras que el ritmo del viaje -y las condiciones que podían rodearlo ${ }^{19}$ - imponía unas restricciones a su tarea, éstas quedaban muy atemperadas cuando disfrutaba -como en Sevilla y en Granada- de mucho tiempo libre que dedicar a sus aficiones, desde el perfeccionamiento del idioma hasta el coleccionismo de arte, pasando, lógicamente, por su faceta artística.

A partir de aquí podemos trazar una cronología de la obra sevillana de Ford, que se convierte también, en cierta medida, en una topografía de la misma. Observamos, en primer lugar, una serie de bloques temáticos que construyen itinerarios urbanos: uno de los más definidos es el que da inicio a la serie, y que se desarrolla entre diciembre de 1830 y el mes de enero siguiente. Para un Ford acostumbrado a las vistas desde la distancia, el reconocimiento de la ciudad debe iniciarse por sus bordes, y en concreto por los espacios cercanos al perímetro de la muralla

Antonio: “Granada", en RODRÍGUEZ BARBERÁN, F. Javier (ed.): Richard Ford..., op. cit., pp. 140-143.

${ }^{17}$ En la exposición de 2007, los diferentes artículos del catálogo abordan los temas de Ford, pero no hay una secuencia temporal de las obras. Vid. RODRÍGUEZ BARBERÁN, F. Javier (ed.): La Sevilla ..., op. cit.

${ }^{18}$ Ibídem, p. 41 (cat. n ${ }^{\circ} 14$ ).

${ }^{19}$ Así, por ejemplo, una carta, fechada en junio de 1832 y dirigida desde Salamanca a su amigo Henry Unwin Addington, se queja de que en el viaje está siendo permanentemente acompañado por el viento y la lluvia, que hacen volar los papeles y los empapan hasta hacerlos inútiles, por no hablar "(del miedo ante) la posibilidad de recibir un disparo como si fuera un espía". Vid. PROTHERO, Rowland E. (ed.): The Letters of Richard Ford 1797-1858. London, 1905, p. 93. 
almohade y las puertas. Los terrenos que rodean la ciudad le permiten observar los sucesivos planos de ese suelo carente en muchos casos de vegetación, de la cerca y de los edificios que destacan sobre ella. La secuencia le lleva de la Puerta de Carmona (PLANO I / N $\mathbf{N}^{\mathbf{0}}$ 1) a la de Jerez (PL. I / 2), y de ahí a la Puerta Nueva (PL. I / 3), la del Osario (PL. I / 4) y la Puerta Real (PL. I / 5). El dibujo de ésta, fechado el 22 de diciembre, es muy revelador no tanto por lo que muestra-que es mucho ${ }^{20}$, sino por aquello que decide, de algún modo, obviar. El lugar le interesa, y ello va a demostrarlo cuando pocos días después dedique un apunte a los restos del convento de S. Laureano; sin embargo, la vista de la Puerta Real desde el interior, una de sus obras más conocidas, no será ejecutada hasta el verano de $1832{ }^{21}$. ¿Cuál es la interpretación que podemos hacer de esto? Que hay una cierta lógica en el proceder del viajero. Ford ha decidido retratar los bordes de la ciudad de un modo casi sistemático: es cierto que hay ausencias difíciles de explicar, como el hecho de que ningún dibujo se ocupe del área comprendida entre la Puerta de la Macarena -fuera del registro del viajero- y la Puerta Real con la excepción de una vista de la Cartuja desde la margen izquierda del río, fechada ya en el mes de enero de $1831^{22}$. Sin embargo, la secuencia de lo realizado no admite dudas. En ese mismo mes de enero nos encontramos con sus dibujos de la Puerta de la Carne (PL. I / 8), la zona del Cristina con el Palacio de S. Telmo (PL. I / 7) y las murallas entre la Puerta de Córdoba y la de la Macarena (PL. I / 9 y 10) ${ }^{23}$; a éstos se añadirán otros que muestran analogías con lo sucedido en el caso de la Puerta Real y S. Laureano: me estoy refiriendo al apunte de la iglesia de Sta. Lucía (PL. I / 6) y al que retrata el abandonado interior de la Puerta del Sol (PL. I / 11) ${ }^{24}$. Son imágenes intramuros, pero como en el caso de S. Laureano, nos muestran una ciudad decaída a través de un sector de la misma marcado por la pobreza y por los estragos del tiempo, y que tiene más de periferia que de centro.

A partir de aquí la mirada de Ford sobre la ciudad se bifurca, o más bien parece adaptarse a dos realidades que conviven en él: la continuidad de su proyecto descriptivo y la voluntad de buscar un registro artístico en la expresión. A finales

${ }^{20}$ RODRÍGUEZ BARBERÁN, F. Javier (ed.): La Sevilla..., op. cit., p. 186 (cat. no 111). Un análisis monográfico de los dibujos relacionados con las murallas y puertas de la ciudad puede verse en JIMÉNEZ MAQUEDA, Daniel: "Las murallas y las puertas", en Ibídem, pp. 167-189.

${ }^{21}$ Ibid. Véanse, respectivamente, pp. 187 (cat. $\mathrm{n}^{\circ} 144$ ) y 166 (cat. $\mathrm{n}^{\circ} 112$ )

${ }^{22}$ Ibíd., p. 218 (cat. $\mathrm{n}^{\circ}$ 108). El dibujo, fechado el 8 (i) de enero indica literalmente que la vista está tomada desde "near the Huerta de Colón (sic)".

${ }^{23}$ Ibid. Véanse, respectivamente, pp. 177 (cat. n $\left.{ }^{\circ} 94\right), 201$ (cat. $\mathrm{N}^{\circ} 85$ ), 168 (cat. $\mathrm{N}^{\circ} 105$ ) y 169 (cat. ${ }^{\circ} 103$ ).

${ }^{24}$ Ibíd. Vid. pp. 224 (cat. № 170) y 172 (cat. no 102); en este último no figura el día exacto. También, y pese a no estar fechado, el dibujo que muestra el interior de la muralla entre las puertas de Córdoba y de la Macarena (p. 195; cat. $n^{\circ} 106$ ), podría responder a este mismo momento. 
de enero están fechadas dos obras (PL. I / 12 y 13) que eligen prácticamente el mismo emplazamiento pero que difieren en el objeto de la mirada ${ }^{25}$ : partiendo quizás desde la Puerta de Carmona se ha dirigido hacia el oeste hasta llegar a un apeadero situado ligeramente en alto; es el templete denominado la Cruz del Campo. Uno de los dibujos, tomado aproximadamente desde lo que hoy sería la intersección de la avenida de Luis Montoto con las calles Tomás Murube y Marqués de Nervión, nos muestra dicho templete y las muy modestas edificaciones de su entorno, hoy transformado hasta hacerlo casi irreconocible; el otro apunte surge tras haber recorrido unos pocos metros, cuando se detiene ante el camino luego tan frecuentado por Ford en sus viajes hacia Granada. Hay, en un sentido que combina lo literal con lo metafórico, una cierto tono de inicio para otra serie, que será la que, sobre todo a lo largo de marzo, muestre la ciudad como parte del extenso paisaje que se extiende a partir de la cornisa del Aljarafe. No obstante, para la iconografía urbana tienen mucha más relevancia un grupo de obras con una personalidad propia perfectamente definida, y que son ejecutadas en el plazo de un mes, entre mediados de febrero y las mismas fechas de marzo ${ }^{26}$. En este caso la técnica es la de la acuarela, de la cual Ford solo poseía por entonces conocimientos muy elementales; de hecho, una parte importante de las obras de temas españoles realizadas por él con dicha técnica son en realidad una reelaboración, hecha en Inglaterra, de algunos de sus dibujos ${ }^{27}$. Por orden cronológico, las representaciones de la iglesia del Monasterio de Sta. Paula - con su conocida portada de ladrillo y cerámica renacentista-, de la iglesia de S. Andrés, de las antiguas Carnicerías y de la entonces llamada "Casa de Murillo" (PL. I / 14 a 17 respectivamente), nos aproximan a otro Ford. Hablamos del que, como las páginas de su Manual se encargarán de poner de relieve años después, está interesado en las bellezas monumentales de la ciudad -y de España en general-, y encuentra además que la mejor manera de ponerlas de relieve es darles un perfil de representación diferente. Si alguna vez se han señalado las diferencias entre estas obras realizadas aquí y las ejecutadas en Inglaterra, ahora nos interesa poner mucho más de relieve una lectura que sitúe estas acuarelas de Ford como prólogo

${ }^{25}$ Para un análisis detallado de estos dibujos y, en general, de la lectura de Ford del paisaje exterior de Sevilla, MÁRQUEZ, Francisco y CASCALES, Juan: "La mirada sobre su territorio", en Ibíd.; para este caso concreto, véanse sobre todo pp. 162-165.

${ }^{26}$ Aunque no se comenten de modo específico, es muy interesante advertir que, entre las dos series, Ford realiza dos dibujos - uno de ellos fechado el 9 de febrero-realmente singulares, en los cuales retrata el primer cementerio extramuros estable de la ciudad, el de S. Sebastián. Vid. RODRÍGUEZ BARBERÁN, F. Javier: "El cementerio de San Sebastián”, en Ibíd., pp. 247-251.

${ }^{27}$ Vid. FORD, Brinsley: "Richard Ford as a Draughtsman", en Idem: Richard Ford ...., op. cit., pp. 31-35. También este tema ha sido revisado en RODRÍGUEZ BARBERÁN, F. Javier: "Una colección invisible...”, op. cit., especialmente pp. 44-47. 
para un género que va a surgir entonces en nuestro país, animado primero por los artistas extranjeros y cultivado después por los autores españoles que siguen su estela: nos estamos refiriendo a las vistas de monumentos en las ciudades de la Península, camino iniciado por pintores como los ya citados Lewis y Roberts, y que darán pronto frutos con las obras de Genaro Pérez Villaamil o de Domínguez Bécquer en el ámbito sevillano ${ }^{28}$.

El interés del doble perfil que ofrece este bloque cronológico de imágenes de la capital andaluza es que muestra un proceder deliberado, que irá incluso más allá de este momento. En efecto, la serie se interrumpe porque los viajes y las estancias de toda la familia en Granada lo separan de la ciudad: entre abril de 1831 y los primeros días de diciembre de este mismo año -salvo un breve paréntesis de apenas dos semanas en el mes de mayo-, Richard Ford estará fuera de la ciudad. Al año siguiente, una gira por rutas andaluzas abarcará buena parte del mes de marzo, y después, de mayo a julio estará ocupado con un viaje que tiene como elemento clave la antigua Ruta de la Plata ${ }^{29}$. Sin embargo, los dibujos sevillanos fechados en 1832 parecen retomar el camino aun no completado. En cierta medida podemos analizarlos como parte de un proyecto que hubiera quedado inconcluso de no surgir la posibilidad de continuar trabajando en él, y que responde a unos patrones análogos a los que reconocimos en las obras de 1831 . Vuelve -con dibujos fechados en mayo y octubre de 1832- el observador de los bordes urbanos, que presta atención ahora a las orillas del río y a la zona de las Delicias (PLANO II I Números 1 y 2), o que retorna a los reconocibles vacíos extramuros del Prado de S. Sebastián o de las inmediaciones de la antigua Fábrica de Salitre (PL. II / 16 y 15) ${ }^{30}$. Pero sobre todo nos encontramos con que, roto simbólicamente el cerco de las murallas, la ciudad interior, con sus espacios públicos, adquiere un enorme relieve: los dibujos -casi todos fechados en el mes de agosto, aunque también existe alguno de octubre- no están centrados en el atractivo de lo monumental, sino en los escenarios urbanos que componen edificaciones singulares, modestas arquitecturas domésticas, calles, plazas y -con las limitaciones, eso sí, que Ford tiene como artista- los personajes que habitan en ellas. En lugar de las estancias del Alcázar aparece su muralla y la plaza del Triunfo (PL. II / 4 y 5); el propio Alcázar y la antigua Lonja ceden el protagonismo a la Torre de Abd el Aziz y el Arquillo de la Plata (PL. II / 3) ; la Puerta Real y la de Triana (PL. II / 8 y 14), vistas desde

${ }^{28}$ Una aportación muy reciente a este tema, a partir de una obra con fuertes puntos de contacto con el mundo de Ford, puede verse en BARÓN, Javier: Genaro Pérez Villaamil. Díptico con vistas de ciudades españolas. Madrid, 2014.

29 Para una cronología actualizada de los viajes por España, véase ROBERTSON, Ian: "Richard Ford (1796-1858)", en RODRÍGUEZ BARBERÁN, F. Javier (ed.): Richard Ford..., op. cit., pp. 12-20.

${ }^{30}$ RODRÍGUEZ BARBERÁN, F. Javier (ed.): La Sevilla..., op. cit..Véanse, respectivamente, pp. 155 (cat. $\mathrm{n}^{\circ} 80$ ), 148 (cat. $\mathrm{N}^{\circ} 84$ ), 246 (cat. $\mathrm{N}^{\mathrm{o}} 87$ ) y 242 (cat. $\mathrm{n}^{\circ} 101$ ). 
el interior de la ciudad, son representadas en su contexto urbanístico, el mismo que cobra un inesperado protagonismo en calles como la del Sacramento o plazas como la de Villasís (PL. II / 7 y 12); la Plaza de Toros y la Torre del Oro aparecen indecisas entre el borde urbano y la cercanía de la ciudad edificada (PL. II / 9 y 11); las columnas romanas son solo una parte del paisaje de la Alameda (PL. II I10); y las propias casas donde habitó la familia Ford se convierten en elementos para componer perspectivas de la calle Monsalves o de la plazuela existente junto a la iglesia de S. Isidoro (PL. II / 6 y 13) ${ }^{31}$. Es evidente que, en la línea de lo apuntado con anterioridad, la forma de mirar que estos dibujos revelan tiene que ver con lo que está a punto de convertirse, como ya se ha señalado, en un tema clave para la pintura española de la primera mitad del XIX, es decir, las vistas urbanas. No obstante, este bloque -que muestra también una evolución de la técnica si lo comparamos con las primeras obras sevillanas- sigue transmitiendo la sensación de que la tantas veces debatida adjetivación de Ford como viajero romántico debe ser considerada con prudencia ${ }^{32}$. Lo más atractivo del conjunto es la enorme información que cada dibujo nos transmite, al permitirnos visualizar espacios que solo serán documentados de un modo objetivo cuando, al menos dos décadas después, la fotografía se extienda como técnica de captación de la imagen; e incluso así, algunos de dichos espacios ni siquiera tendrán ese privilegio: solo contarán durante décadas con la mirada de Ford, ya que no llegarán a merecer ni la atención de la pintura ni la del nuevo medio. Y es aquí cuando inevitablemente surge otro tema recurrente desde que la obra del viajero inglés fue conocida: la objetividad de sus representaciones. No podemos negar que hay en ellas una núcleo esencial que apela a esta característica ${ }^{33}$, pero para afirmar esto es necesario establecer una sistema de verificación. Como es lógico, y pese a todas las salvedades que históricamente se han planteado en torno al concepto de verdad fotográ$\mathrm{fica}^{34}$, parecería lo más adecuado medir el grado de precisión y de sinceridad de los dibujos de Ford a partir del medio que mejor va a representar estos parámetros desde que hiciera su aparición en 1839. La tarea, no obstante, presenta obstáculos. En primer lugar, algo que puede ser deducido a partir de un comentario anterior: los intereses del viajero inglés y los de la fotografía, dado el importante componente comercial de ésta al menos hasta el último tercio del XIX, hace que lo que Ford elige sea obviado, o que el punto de vista utilizado por éste no coincida exactamente con el del fotógrafo. El factor de la cronología además no es

${ }^{31}$ Como ejemplos de estos dibujos vid. Ibídem, pp. 232 (cat. ${ }^{\circ} 160$ ), 188 (cat. $n^{\circ} 158$ ), 184 (cat. $\mathrm{n}^{\circ} 113$ ), 193 (cat. ${ }^{\circ} 140$ ) y 134 (cat. $\mathrm{n}^{\circ} 16$ ).

${ }^{32}$ Para una actualización de este tema, véase RODRÍGUEZ BARBERÁN, F. Javier: "Una colección invisible...", op. cit., especialmente pp. 56 y ss.

${ }^{33}$ Ibídem, pp. 41 y ss.

${ }^{34}$ Véase, por ejemplo, el estupendo ensayo del fotógrafo FONTCUBERTA, Joan: $E l$ beso de Judas. Fotografía y verdad. Barcelona, 1997. 
desdeñable: para abordar un análisis más preciso de los dibujos de Ford sería fundamental que las fuentes con las cuales realizar la comparación fueran lo más cercanas posibles a su tiempo. Esto significaría, para el caso de la ciudad de Sevilla, que en las imágenes tomadas por el Vizconde de Vigier, Charles Clifford o J. Laurent, por citar solo a los autores más conocidos del registro fotográfico de la ciudad en el segundo tercio del siglo XIX ${ }^{35}$, hubiera visiones compatibles con las de Ford: lamentablemente esta posibilidad solo se presenta en muy contadas ocasiones. La fotografía opta casi siempre por la singularidad monumental, dejando el contexto urbano de las obras en un plano secundario; y si muestra espacios públicos, prefiere los más abiertos o relevantes para la imagen oficial de la ciudad, lo cual invalida el paralelismo con tantas vistas periféricas -en sentido real y también metafórico- de Ford. Lo que sí podemos verificar es que cuando esta lectura comparativa es parcialmente viable, el grado de fiabilidad de los dibujos parece elevado: éste sería el caso de los dos dedicados a la Alameda de Hércules, cuya comparación con la fotografía tomada por Laurent hacia 1876 resulta muy favorable a una percepción objetiva por parte de Ford ${ }^{36}$. Ahora bien, dicha percepción no debe hacernos olvidar que, en un sentido figurado, el viajero inglés utiliza una lente cuyo ángulo de visión es claramente más amplio que el de su propio ojo. Los dibujos, por tanto, no mienten en cuanto a lo existente, pero sí que son el resultado de una mirada que reúne fragmentos de la realidad para, por medio de la perspectiva, unificarlos en una representación única.

Lo que cabría valorar entonces -y desde luego para ello sería necesario un espacio mucho más extenso que el del presente artículo- son los límites de Richard Ford como dibujante, y de modo muy particular su dominio del mecanismo de la perspectiva. Evidentemente esto no significa invalidar su gran aportación, sino someter la obra a unos mecanismos de interpretación que, en cierta medida, aun no han sido suficientemente utilizados. Algo así, por ejemplo, no le restaría importancia a la vertiente como documentalista de un patrimonio desaparecido o fuertemente transformado, del mismo modo que su manifiesta debilidad a la hora de representar la figura humana nunca ha disminuido el interés que sus dibujos han suscitado. Y por el contrario, una lectura como ésta quizás nos permitiera entender mejor determinadas ausencias -los interiores de los edificios- o

${ }^{35}$ Un panorama de los mismos puede verse en AA VV: Fotógrafos en la Sevilla del siglo XIX. Sevilla, 1994. Para una visión actualizada de estos autores en el contexto de la fotografía de la época, vid. PÉREZ GALLARDO, Helena: Fotografía y arquitectura del siglo XIX. Historia y representación monumental. Madrid, 2015.

${ }^{36}$ RODRÍGUEZ BARBERÁN, F. Javier (ed.): La Sevilla..., op. cit.. Véanse, respectivamente, pp. 192 (cat. ${ }^{\circ} 139$ ) y 193 (cat. $\mathrm{n}^{\circ} 140$ ). La imagen de Laurent puede verse en AA VV: Sevilla artística y monumental 1857-1800. Fotografías de J. Laurent. Madrid, 2008, p. 189. 
persistencias - las vistas de ciudades desde la distancia o el interés, en el caso de Sevilla, por su perímetro urbano-en su producción.

Al concluir, vaguemos hoy por la ciudad como Ford hizo más de ciento ochenta años atrás. Aproximemos nuestra mirada, en la medida de lo posible, a la de nuestro antecesor, e imaginemos, por ejemplo, que la plaza de Fernando de Herrera no es más que la del viejo Cementerio de S. Andrés ${ }^{37}$, y así, en ese espacio entonces tan reducido, veamos de qué modo el viajero inglés construyó la imagen del templo a partir de una suma de puntos de vista. Visitemos los lugares en los que la familia Ford habitó, y prestemos atención, más que al juego de permanencias y transformaciones, a la manera en que fueron trasladados por él al papel: la fidelidad con que muestra la plaza junto a la iglesia de S. Isidoro y la sorprendente transformación de Monsalves en una calle ancha, fugada hacia la distancia, frente a su angostura real. O salgamos finalmente del núcleo histórico y apreciemos de qué modo, junto a las murallas, y no lejos del convento de Capuchinos y de la iglesia de S. Hermenegildo, su visión y la nuestra son casi coincidentes. Lógicamente, los resultados aparecen marcados por la irregularidad y pueden resultar falsamente decepcionantes, quizás porque deseamos que, contra su propia naturaleza, Ford sea el artista cultivado y el topógrafo preciso que no fue. El registro, de todos modos, conserva su enorme valía: hacer que dos ciudades, separadas casi por dos siglos, puedan convivir con naturalidad ante nuestros ojos.

Fecha de recepción: 16 de septiembre de 2014

Fecha de aceptación: 28 de noviembre de 2014

${ }^{37}$ VIOQUE CUBERO, Rafael et al.: Apuntes sobre el origen y evolución morfológica de las plazas del casco histórico de Sevilla. Sevilla, 1987, pp. 68-69. Para la información general histórica sobre los espacios urbanos que van a ser comentados, vid. AA VV: Diccionario histórico de las calles de Sevilla. Sevilla, 1993. 


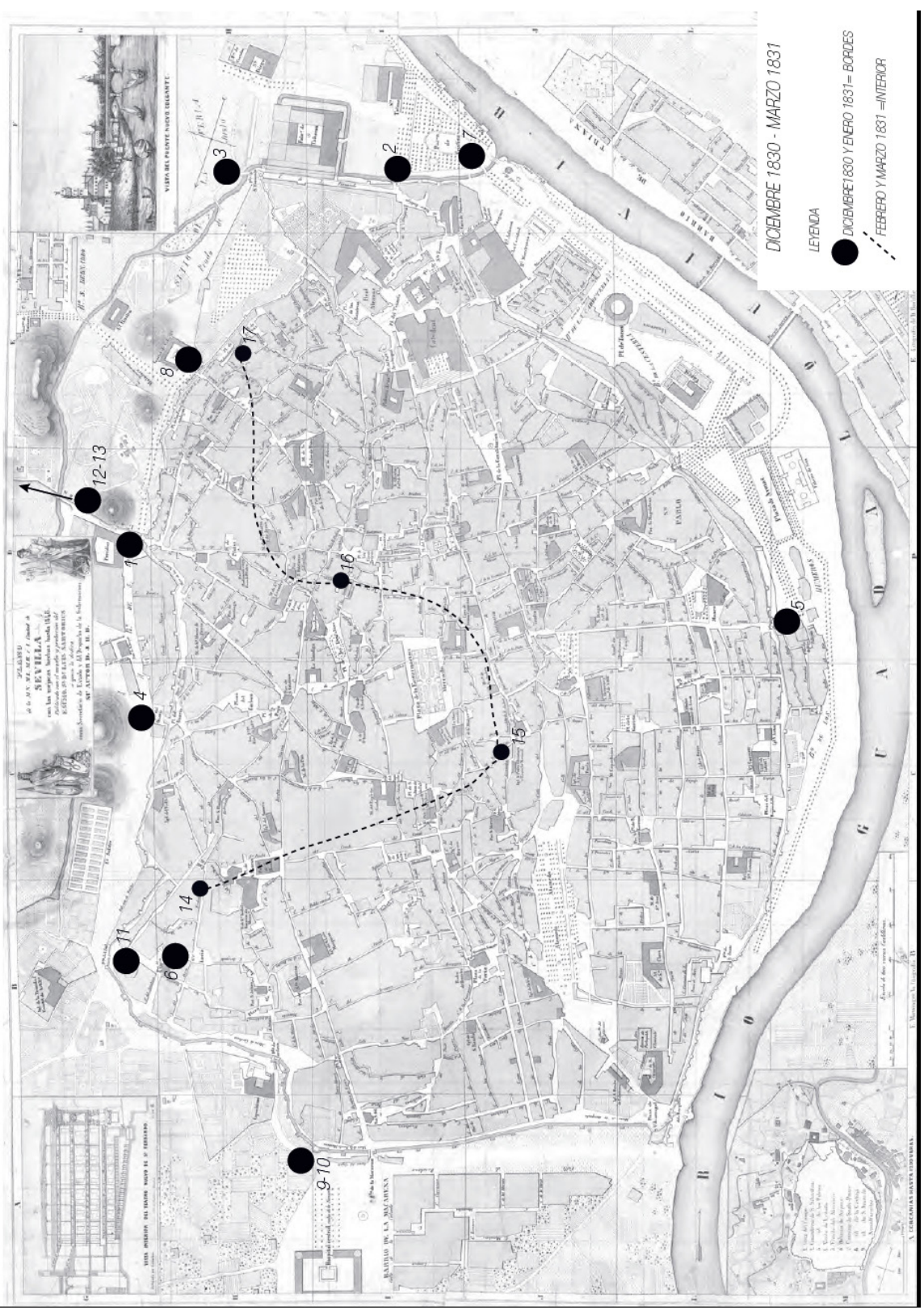

Figura 1. PLANO I. Reconstrucción de los itinerarios de R. Ford por la ciudad. Años 1830-1831 (sobre el plano de José Herrera Dávila de 1848). Elaboración propia. 


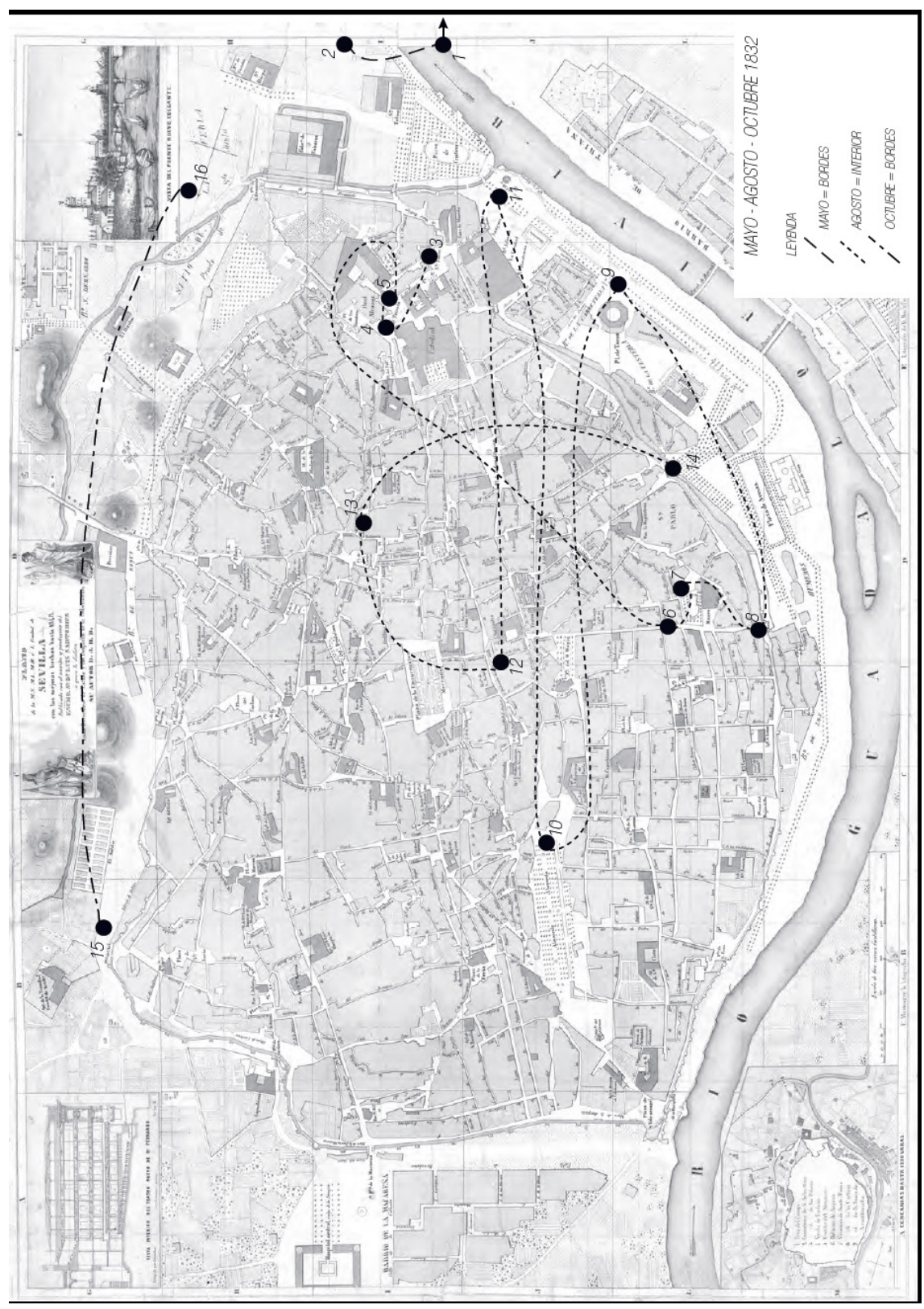

Figura 2. PLANO II. Reconstrucción de los itinerarios de R. Ford por la ciudad. Año 1832 (sobre el plano de José Herrera Dávila de 1848). Elaboración propia. 


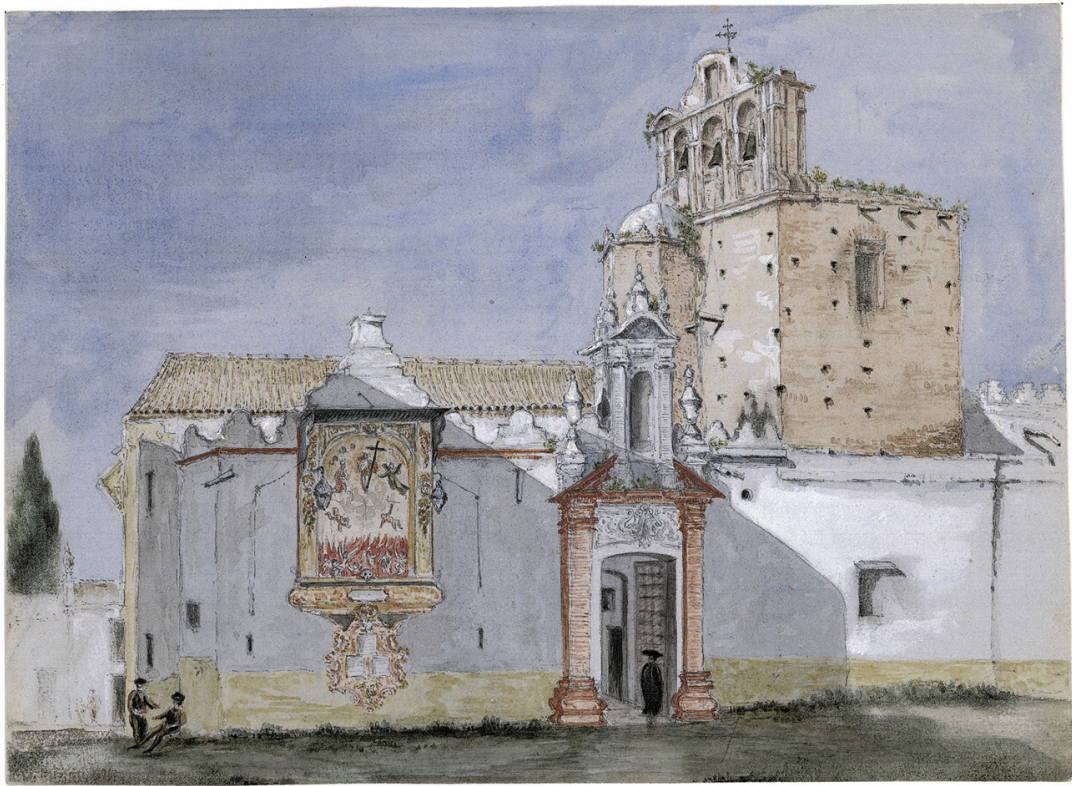

Figura 3. Richard Ford. Iglesia de S. Andrés. Colección de la familia Ford, Londres.

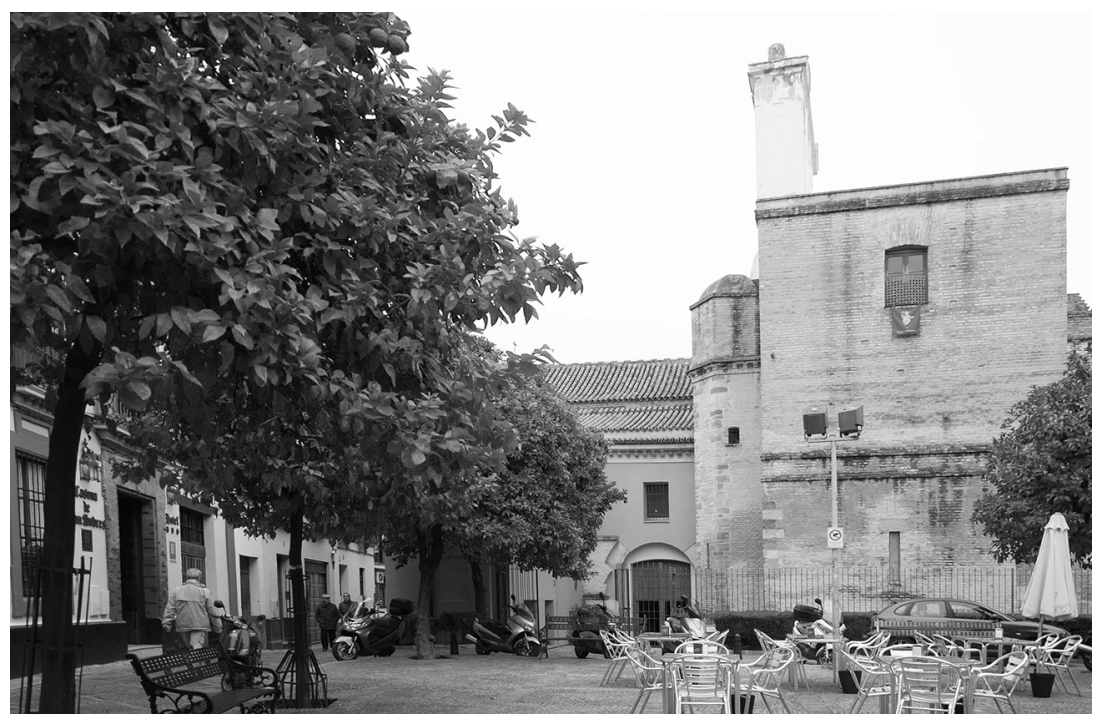

Figura 4. La iglesia de S. Andrés desde la plaza Fernando de Herrera, hoy. 


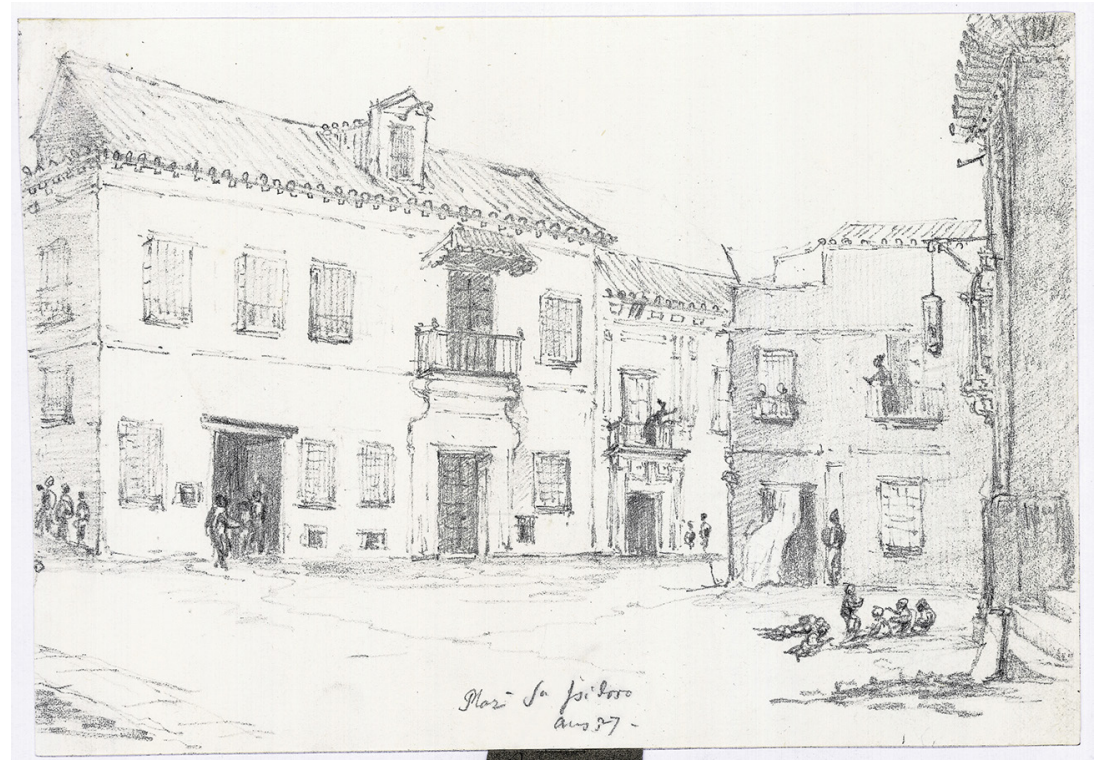

Figura 5. Richard Ford. Plazuela de S. Isidoro. Colección de la familia Ford, Londres.

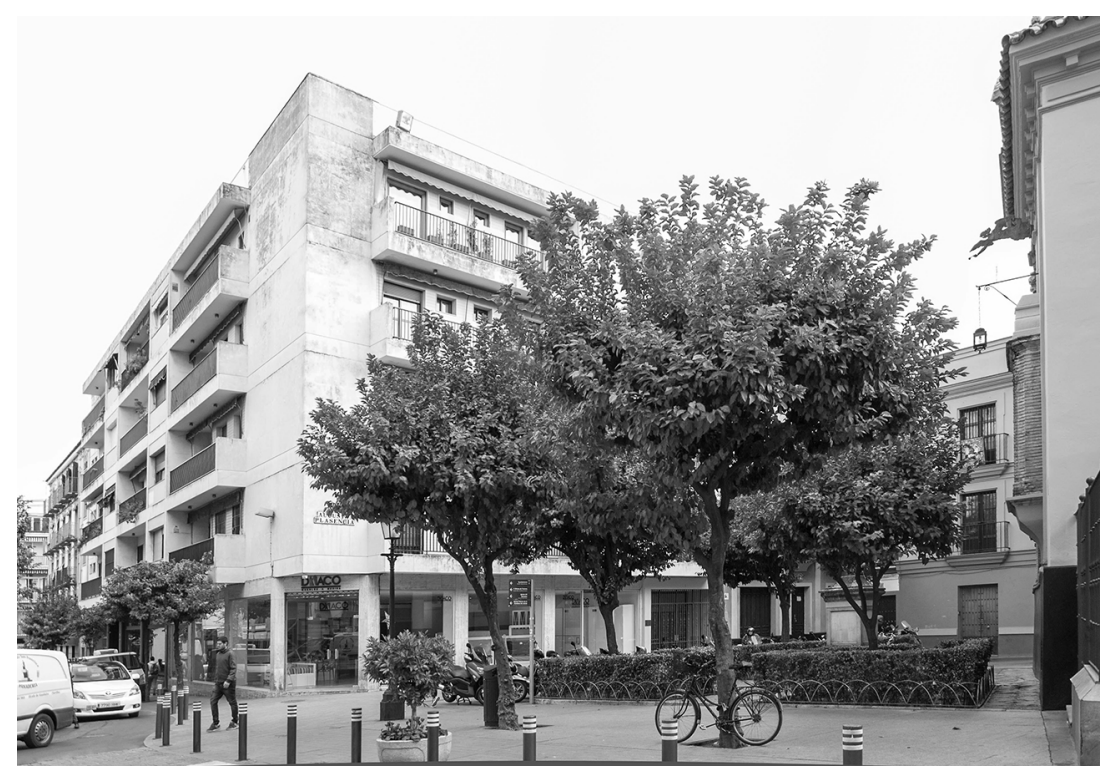

Figura 6. La calle Augusto Plasencia, junto a la iglesia de S. Isidoro, en la actualidad. 


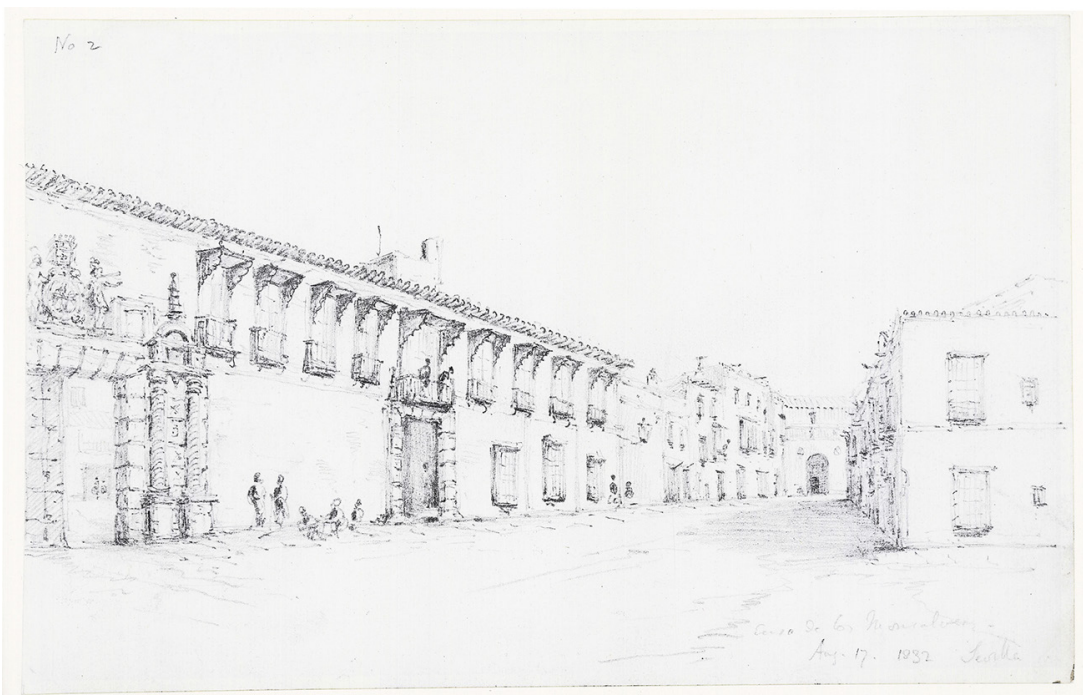

Figura 7. Richard Ford. Palacio y calle de los Monsalves. Colección de la familia Ford, Londres.

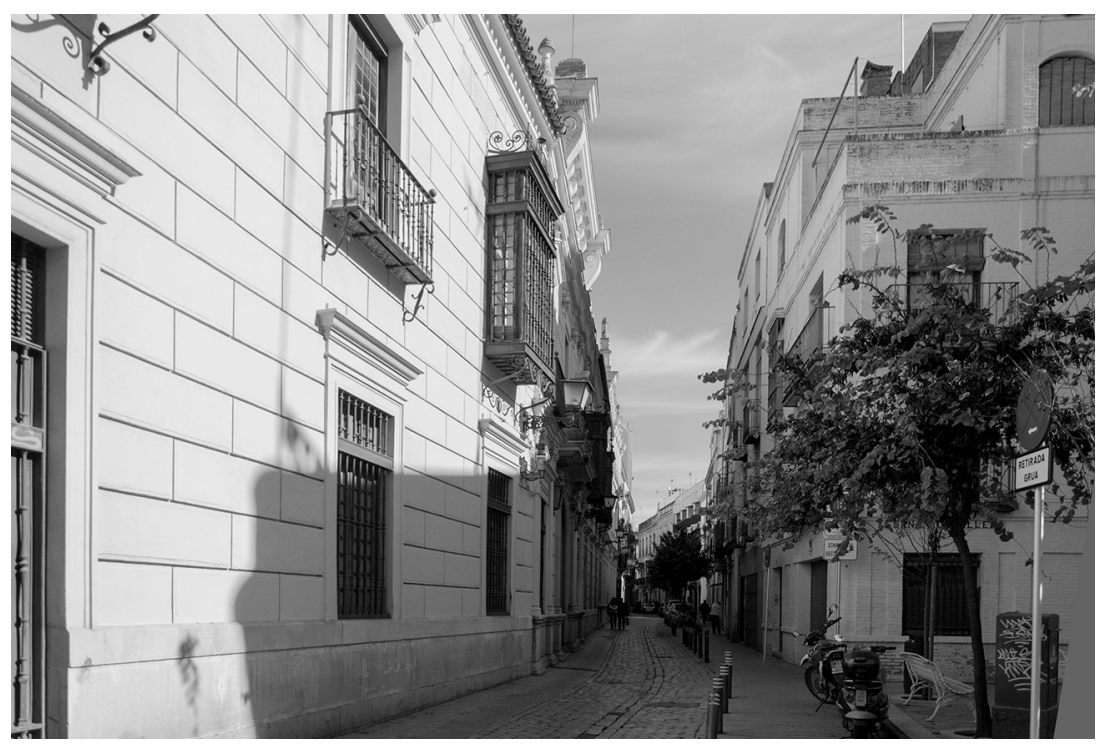

Figura 8. La calle Monsalves, hoy. 


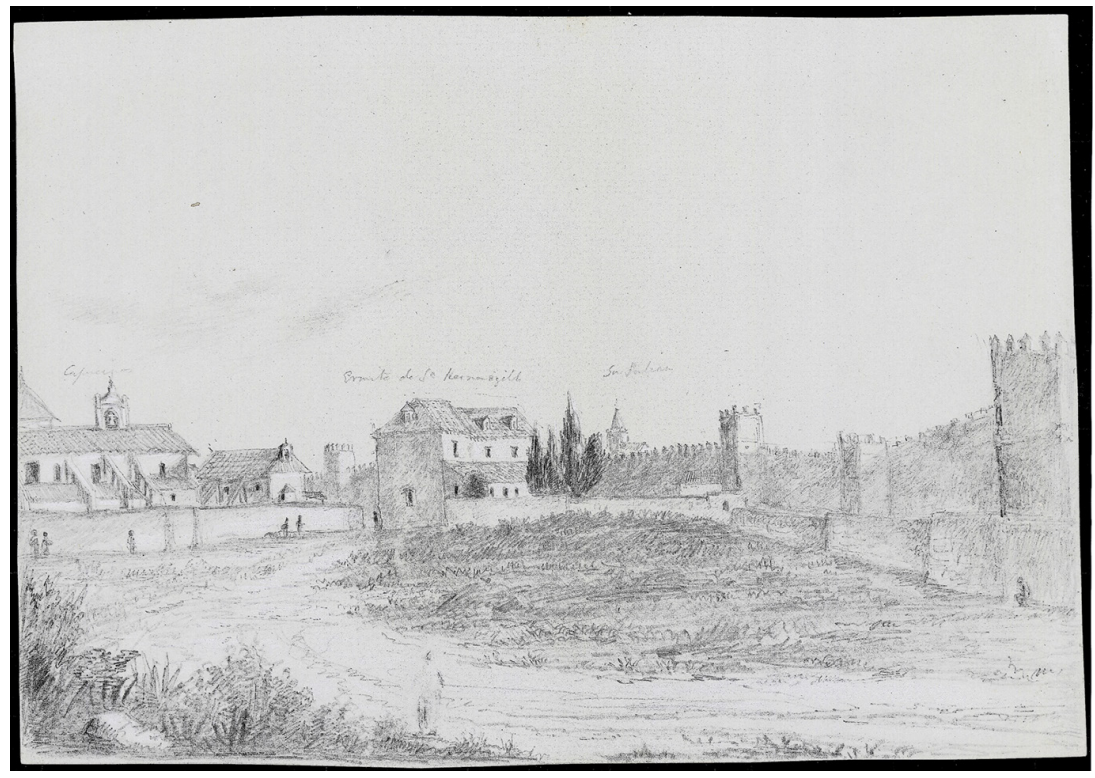

Figura 9. Richard Ford. Convento de Capuchinos, S. Hermenegildo y murallas. Colección de la familia Ford, Londres.

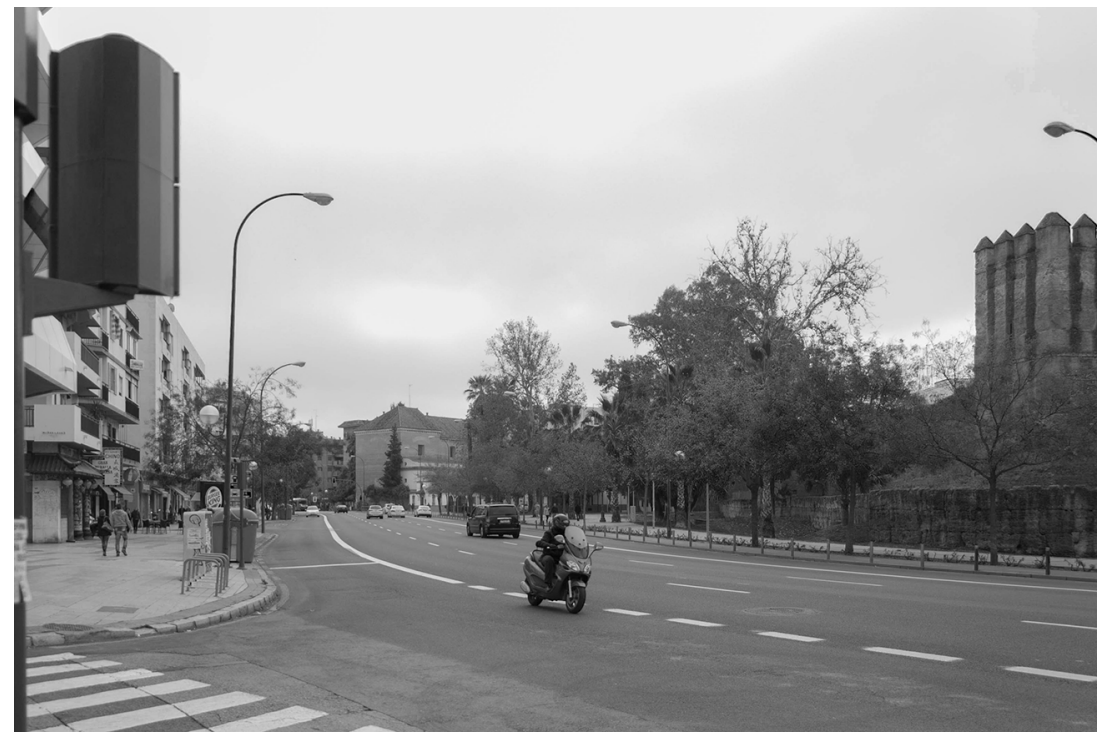

Figura 10. La Ronda de Capuchinos en la actualidad. 